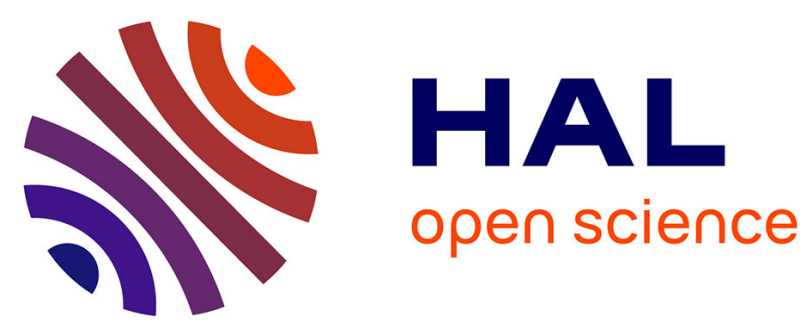

\title{
Laminar Flame Speeds and Ignition Delay Times of Gasoline/Air and Gasoline/Alcohol/Air Mixtures: The Effects of Heavy Alcohol Compared to Light Alcohol
}

Andrea Comandini, Damien Nativel, Nabiha Chaumeix

\section{- To cite this version:}

Andrea Comandini, Damien Nativel, Nabiha Chaumeix. Laminar Flame Speeds and Ignition Delay Times of Gasoline/Air and Gasoline/Alcohol/Air Mixtures: The Effects of Heavy Alcohol Compared to Light Alcohol. Sustainable Energy \& Fuels, 2021, 35 (18), pp.14913-14923. 10.1021/acs.energyfuels.1c01708 . hal-03385120

\author{
HAL Id: hal-03385120 \\ https://hal.science/hal-03385120
}

Submitted on 19 Oct 2021

HAL is a multi-disciplinary open access archive for the deposit and dissemination of scientific research documents, whether they are published or not. The documents may come from teaching and research institutions in France or abroad, or from public or private research centers.
L'archive ouverte pluridisciplinaire HAL, est destinée au dépôt et à la diffusion de documents scientifiques de niveau recherche, publiés ou non, émanant des établissements d'enseignement et de recherche français ou étrangers, des laboratoires publics ou privés. 


\title{
Laminar flame speeds and ignition delay times of gasoline/air and
}

\section{gasoline/alcohol/air mixtures: the effects of heavy compared to light}

\author{
alcohol \\ A. Comandini ${ }^{1}$, D. Nativel ${ }^{1,2}$, N. Chaumeix ${ }^{1, *}$ \\ ${ }^{1}$ Institut de Combustion, Aérothermique, Réactivité et Environnement (ICARE), CNRS-INSIS, 1C avenue de la \\ Recherche Scientifique, 45071 Orléans Cedex 02, France \\ ${ }^{2}$ now at IVG, Institute for Combustion and Gas Dynamics - Reactive Fluids, University of Duisburg-Essen, Carl-Benz- \\ Str. 199, 47057 Duisburg, Germany
}

\author{
*Corresponding Author: \\ Nabiha Chaumeix \\ Centre National de la recherche scientifique \\ Institut de Combustion, Aérothermique, Réactivité et Environnement \\ $1 \mathrm{C}$, avenue de la recherche scientifique \\ 45071 Orléans cedex 2 \\ FRANCE \\ Phone: $+33(0) 238255423$ \\ Fax: +33 (0) 238696004 \\ Email: chaumeix@cnrs-orleans.fr
}




\title{
Laminar flame speeds and ignition delay times of gasoline/air and
}

\section{gasoline/alcohol/air mixtures: the effects of heavy compared to light}

\author{
alcohol \\ A. Comandini ${ }^{1}$, D. Nativel ${ }^{1,2}$, N. Chaumeix ${ }^{1, *}$ \\ ${ }^{1}$ Institut de Combustion, Aérothermique, Réactivité et Environnement (ICARE), CNRS-INSIS, 1C avenue de la \\ Recherche Scientifique, 45071 Orléans Cedex 02, France \\ ${ }^{2}$ now at IVG, Institute for Combustion and Gas Dynamics - Reactive Fluids, University of Duisburg-Essen, Carl-Benz- \\ Str. 199, 47057 Duisburg, Germany
}

\begin{abstract}
The oxidation of gasoline and gasoline/alcohol blends is studied in a shock tube and a spherical reactor. A commercial oxy-free gasoline and two alcohols (ethanol and iso-pentanol) were used in this study. The spherical reactor experiments were conducted at an initial temperature of 483 $\mathrm{K}$, initial pressure of $0.1 \mathrm{MPa}$, and equivalence ratios from 0.65 to 1.36 . Ignition delay times were measured behind reflected shock waves. The shock tube experiments were conducted at $2 \mathrm{MPa}$ over a temperature range from 955 to $1284 \mathrm{~K}$ and for two equivalence ratios $(0.5$ and 1$)$. The experimental measurements indicate that replacing ethanol by iso-pentanol on a gasoline/alcohol blend results in flame speeds which are closer to the ones of a commercial gasoline at nearly stoichiometric conditions (an in-engine applications). On the other hand, the ignition delay times are more affected by the presence of iso-pentanol than the ethanol case. Two different surrogate fuels composed of n-heptane, iso-octane, and toluene were also tested against the newly obtained experimental results (oxy-free gasoline and mixtures with ethanol) using kinetic modeling with a reduced model [L. Cai, H. Pitsch, Combust. Flame 162 (2015) 1623-1637]. While a good agreement between real fuel and surrogate properties was observed for the laminar flame speeds, discrepancies were obtained between the measured and calculated ignition delay times especially in the lower temperature range of our study. Additional simulation analyses on the ignition delay times were
\end{abstract}


performed with a different chemical kinetic model (detailed LLNL model for gasoline surrogates) and a more-complex four-component surrogate. The results show a considerable improvement in the prediction capabilities of the ignition properties of the oxy-free gasoline and the oxy-free gasoline + ethanol mixtures. The ignition delay time data are also in agreement with the correlations provided in the literature for gasoline fuels and their surrogates.

Keywords: Bio-fuels, Renewable fuels, iso-pentanol, gasoline, ethanol, laminar flame speeds, ignition delay times.

\section{Introduction}

In view of the necessity to reduce greenhouse effects and the possibility to develop renewable sources of oxygenated fuels, their blending with gasoline is becoming a common as well as necessary practice worldwide. Besides engine modifications to allow an efficient use of the new blended fuels, the study of the fuel combustion properties is an important subject of investigation in order to foresee any fuel reformulation (with blending amount as high as $20 \% \mathrm{v} / \mathrm{v}$ ) that could be necessary in order to comply with the present and future environmental regulations. Today, ethanol is the most commonly used biofuel. However, its rather low energetic density is a major drawback for the users. To overcome this aspect, the use of heavier alcohols with higher energy densities such as iso-pentanol could be a solution if suitable supply sources are developed [1]. The Research Octane Number (RON) for ethanol, iso-pentanol and a typical commercial gasoline are 109 [2,3], 94 [3] and 88-98 [3], respectively, while the Motor Octane Number (MON) are 90, 84, and 80-88, respectively. This suggests the use of iso-pentanol as a better solution compared to ethanol in view of the higher energy density (21.4 MJ/L and 27.8 MJ/L [4] for ethanol and iso-pentanol, respectively, compared to 30-33 $\mathrm{MJ} / \mathrm{L}$ for gasolines) without degradation of the octane rating [5] (iso-pentanol and gasolines have similar RON and sensitivity $\mathrm{S}=\mathrm{RON}-\mathrm{MON})$. On the other hand, the lower RON of 
iso-pentanol compared to ethanol is a drawback for the use of such biofuel as its addition will not improve the octane rating of the commercial fuels. In the recent years, a large number of studies concerning the combustion of ethanol and gasoline-ethanol blends have been published. The review article on alcohol combustion by Sarathy [3] contains a detailed summary of these investigations. In particular, more and more interest has also been addressed to the combustion properties of gasolines. The first high-temperature shock tube study reporting ignition delay time measurements of gasoline/air mixtures was performed by Gauthier et al. [6] at pressures between 15 and 60 atm, from fuel lean to fuel rich conditions. This study was subsequently complemented with experimental results from the same research group on different gasolines [7-8]. In particular, the recent work by Davidson et al. [7] reports very high-pressure (up to $250 \mathrm{~atm}$ ) ignition delay time measurements and species time-history profiles on four gasolines characterized by very different compositions, including three oxy-free fuels. Cai et al. [9] studied the RON95E10 fuel supplied by Shell Global Solutions $\mathrm{GmbH}$ in a rapid compression machine and a shock tube, comparing the results with and without addition of exhaust gas recirculation (EGR) gases. A similar combination of experimental techniques was used by Sarathy et al. [10-11] to investigate the ignition properties of FACE (Fuels for Advanced Combustion Engines) gasolines. Concerning the laminar flame speed measurements of gasoline/air mixtures, Jerzembeck et al. [12] used a spherical reactor to monitor the propagation of gasoline/air and surrogate/air mixtures at an initial temperature of $373 \mathrm{~K}$ and initial pressures from 10 to 25 bar. A similar technique was implemented by Manaa et al. [13] to study the properties of three FACE fuels at initial temperature and pressure of $358 \mathrm{~K}$ and $0.6 \mathrm{MPa}$. Finally, Sileghem [14] and Dirrenberger et al. [2] studied commercial gasoline fuels at $298 \mathrm{~K}$ and $358 \mathrm{~K}$ with a flat flame adiabatic burner. So far, only pure iso-pentanol experimental studies are reported in the literature [15-20]. In the present study, laminar flame speeds and ignition delay times of gasoline, isopentanol/gasoline and ethanol/gasoline mixtures in air were measured using spherical reactor and 
shock tube techniques, respectively. The experimental datasets obtained herein provide essential information on the fundamental properties of gasoline/alcohol blended fuels at engine relevant conditions which can be also used as a benchmark for future fuel reformulations. In particular, the aim of the study is to understand the effects of blending different oxygenated fuels with a commercial gasoline in terms of the global properties of the fuel itself.

\section{Experimental Facilities}

\subsection{Spherical reactor}

Laminar flame experiments were performed in a $56 \mathrm{~L}$ heated stainless steel spherical vessel made of two concentric spheres, the space between the 2 spheres allows the flowing of a thermal fluid which is regulated to the desired initial temperature. This system permits to fix the initial temperature to any value between 302 and $483 \mathrm{~K}$ and thanks to the circulation pump to ensure the homogeneity over the entire vessel. Two different thermocouples, one at the wall of the vessel and one protruding inside the combustion chamber are used to regulate and monitor the initial temperature with an uncertainty of $\pm 1 \mathrm{~K}$. the facility is insulated to limit the heat losses of the vessel to the ambient temperature and to ensure that no cold spot exist on the entire vessel. The combustion takes place in the inner sphere characterized by an internal diameter of $476 \mathrm{~mm}$. The maximum operating pressure is $5 \mathrm{MPa}$ and a piezo-electric pressure transducer (Kistler 601A) is used to monitor the pressure evolution during combustion. The sensor is mounted flush with the internal surface of the reactor. The ignition of the combustible mixture is obtained via a spark generated by a spark created between two tungsten electrodes linked to a high voltage generator. The average energy delivered by the high voltage generator is $1.82 \mathrm{~mJ}$ with a standard deviation of $0.48 \mathrm{~mJ}$. This energy has been measured using a high voltage probe and a current probe connected to the electrodes. Both $U$ and I signals are recorded on an oscilloscope during the spark formation and hence the energy delivered by the 
spark $\left(E=\int U \cdot I\right)$ is estimated. The spherical reactor is equipped with two opposite quartz windows (100 $\mathrm{mm}$ diameter, $50 \mathrm{~mm}$ thickness). The visualization of the flame was obtained using a Z-shape Schlieren apparatus. A white continuous lamp is used to illuminate the flame via two lenses and two concave spherical mirrors. A high-speed camera (PHANTOM V1610) with an acquisition rate of 25000 images per second records the Schlieren images of the growing flame. The frame size was fixed to $768 \times 768$ pixels $^{2}$. More details can be found in [21-22].

The synchronization of the pressure measurement and the flame recording is obtained by using the voltage breakdown during the spark formation to trigger a TTL (transistor-transistor logic) generator which in turns triggers the camera and the oscilloscopes.

\subsection{Shock tube}

The shock tube has been described in detail in a previous publication [23]. Briefly, experiments were carried out behind reflected shock waves in a stainless-steel shock tube with a $2.00 \mathrm{~m}$ long driver section and a $5.15 \mathrm{~m}$ driven section with a $52.4 \mathrm{~mm}$ internal diameter. This tube is designed for initial pressures up to $4 \mathrm{MPa}$ and initial temperatures up to $403 \mathrm{~K}$. The maximum error in the temperature is $1 \%$, thus around $10-15 \mathrm{~K}$. Both shock tube portions were evacuated using two primary vacuum pumps. Mixtures of helium and nitrogen were used as driver gas, and the shock wave was initiated by the bursting of a double diaphragm. Four piezoelectric pressure transducers (Chimie Metal, Model A25L05B) with a sensitive surface area of $0.75 \mathrm{~mm}^{2}$ and a rise time of $0.4 \mu$ s were used to measure the shock velocity over the last section $(0.7 \mathrm{~m} \mathrm{long})$ and were mounted flush with the inner surface of the tube, the last one being at $10 \mathrm{~mm}$ from the end-wall. The precision on the distance is $\pm 0.1 \mathrm{~mm}$. The very small surface area coupled with a short rise time allows precise determination of the shock wave velocity and, consequently, more accurate evaluation of the temperature and pressure conditions behind the reflected shock wave (reflected shock pressure, 
$\mathrm{P}_{5}$, and temperature, $\mathrm{T}_{5}$, were calculated using the classical shock tube equations [24]). Additionally, a Kistler pressure transducer (model 603B1) is mounted at the end-wall for monitoring of the pressure time-history behind the reflected shock waves. The outputs from the pressure transducers were recorded using two numerical oscilloscopes (Tektronix TDS5034B).

\subsection{Reagents}

For the laminar flames study, the mixtures were prepared inside the spherical reactor using the partial pressure method. The introduction of air creates turbulences that ensured a good mixing of the various components. The waiting time between the introduction of air and the flame ignition was around 5 minutes. Several experiments were repeated for the same initial conditions but increasing the waiting time with no substantial differences in the results. This suggests that the initial mixture is homogeneous while the turbulence levels are too low to play a relevant role in the experimental measurements. Partial pressures of fuel as well as dry air were measured using capacitive manometers (MKS) of two different scales (13.33 and $133.3 \mathrm{kPa})$. For the ignition delay time study, the reactive gas mixtures were prepared manometrically in a $30 \mathrm{~L}$ stainless steel reservoir equipped with magnetic fans to ensure homogeneous composition before injection into the shock tube. Four manometers were used to accurately measure the pressure during the mixture preparation, three MKS Baratron type 631 with different scales $(1.33,13.33,133.3 \mathrm{kPa})$ and one Kistler type 7505 , with a $1 \mathrm{MPa}$ scale. The mixture preparation rig (tubing and reservoir) is heated to a temperature of $423 \mathrm{~K}$ in order to avoid any condensation or adsorption on the walls. For both studies, according to the precision of the manometers, the mixtures were obtained with an accuracy of $99.5 \%$.

As mentioned above, two alcohols were used in the present investigation for blending with gasoline, ethanol (LiChrosolv ${ }^{\circledR}$, Merck $\left.\geq 99.9 \%\right)$ and iso-pentanol (Sigma Aldrich anhydrous $\geq 99 \%$ ). The synthetic air used in the experiments is composed of $20.9 \% \mathrm{O}_{2}+79.1 \% \mathrm{~N}_{2}$ (Air Liquide, grade alphagaz 2, purity $>99.9999 \%$ ). Finally, the gasoline was provided by TOTAL group. The 
main chemical families of the gasoline constituents and its composition expressed in molar percent are reported in Table 1. In particular, no oxygenated compounds are present in the reference gasoline fuel, which in the rest of the manuscript will be called OFG (for OxyFreeGasoline). Its global formula is $\mathrm{C}_{6.384} \mathrm{H}_{11.842}$ and it is characterized by a $\mathrm{RON}$ number equal to 92.5 . A more detailed analysis of the single species present in the gasoline was provided by TOTAL so that the corresponding thermodynamic data and the thermodynamic data of the OFG fuel could be accurately estimated. In particular, 26 species constitute $97.72 \%$ of the total mass percentage. For these species, the thermodynamic properties were taken from the literature data or estimated with the software THERM [25] using the group additivity method.

Table 1

Composition of the gasoline OxyFree (OFG)

\begin{tabular}{cc}
\hline Family component name & mass\% \\
\hline Iso-paraffins & 46.17 \\
Aromatics & 37.96 \\
Naphtenes & 6.38 \\
Paraffins & 4.59 \\
Olefins & 4.32 \\
Cyclo-Olefins & 0.54 \\
Di-Olefins & 0.01 \\
Oxygenates & 0.00 \\
\hline
\end{tabular}

Two different E10 mixtures were prepared by mixing either ethanol or iso-pentanol with the oxy-free gasoline (OFG): the E10 resulting from the ethanol/OFG blend will be labeled E10-Ethanol, the E10 resulting from the blending with iso-pentanol will be labeled E10-Iso-Pentanol. The percentages of ethanol and iso-pentanol in the mixtures are specified in Table 2 and have been chosen in order to match the current commercial E10 gasolines in terms of oxygen content. According to the linear relation for the RON calculation, the RON for E10-Ethanol and E10-Iso-Pentanol mixtures are 95.2 and 92.8 , respectively. 
Alcohol percent (by weight and by volume) in order to obtain a commercial E10 gasoline

\begin{tabular}{ccc}
\hline & Ethanol & Iso-Pentanol \\
\hline $\mathbf{\%} \mathbf{w}$ & $10.64 \%$ & $20.81 \%$ \\
$\% \mathbf{v}$ & $9.90 \%$ & $18.91 \%$ \\
\hline
\end{tabular}

\section{Results and discussions}

\subsection{Laminar flame speeds}

The methodology for the data acquisition and processing was well detailed in recent papers [26, 27]. For this study, the same methodology was adopted. Briefly, the Schlieren images of the growing flames are processed using a home-made code based on Matlab ${ }^{\circledR}[28]$ to determine the evolution of the spatial speed $\mathrm{V}_{\mathrm{S}}=\mathrm{dR}_{\mathrm{f}} / \mathrm{dt}$. Usually between 110 and 350 images are used to derive the flame speed. Great care has been taken when performing these experiments in order to obtain flames that are spherical and without significant distortions. An example of recorded images is given in Fig. 1 together with the corresponding pressure trace. The expansion of the burned gases leads to a substantial increment in the pressure which reaches a maximum value at around 0.8 seconds in the specific case. On the other hand, the flame measurements are obtained over much shorter times, so that the pressure rise during data acquisition is negligible as presented in Fig. 1 (bottom-right graph). 

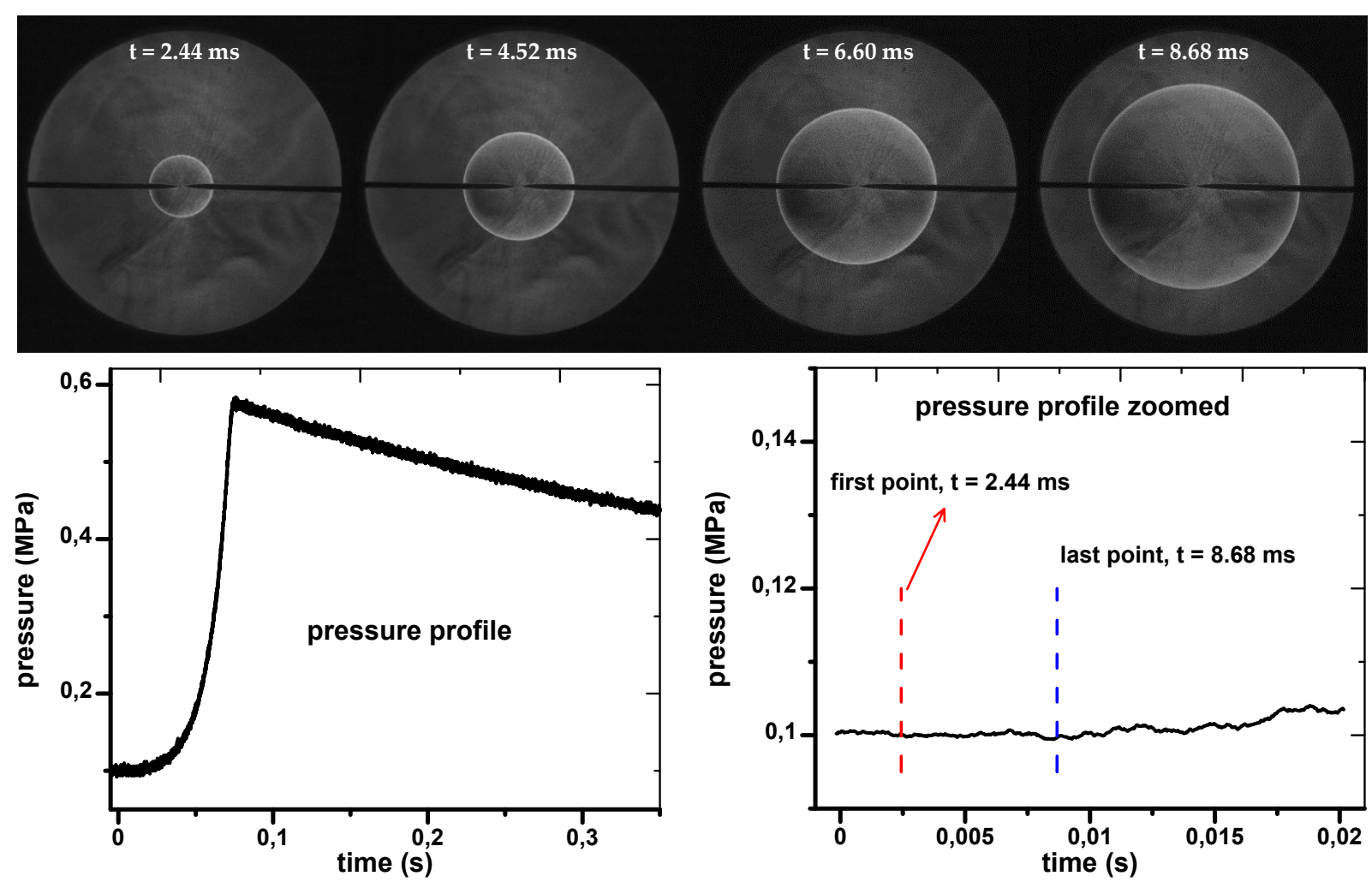

Fig.1. Example of images recorded using the high-speed camera in case of stoichiometric OFG/air mixture and corresponding pressure profile. $P_{i n i}=0.1 \mathrm{MPa}, T_{\text {ini }}=483 \mathrm{~K}$.

For expanding flames, the flame is stretched due to curvature and strain and the total stretch for this configuration is given by $\kappa=2\left(V_{\mathrm{S}} / R_{\mathrm{f}}\right)$. The flame propagation depends on the stretch rate. Knowing this dependence allows to derive the flame speed at zero stretch, $\mathrm{V}_{\mathrm{s}}{ }^{0}$, and $\mathrm{L}_{\mathrm{b}}$, the Markstein length in the burnt gases, derived here with the non-linear relation proposed by Kelley and Law [29]:

$\left(\frac{\mathrm{S}_{\mathrm{b}}}{\mathrm{S}_{\mathrm{b}}^{0}}\right)^{2} \cdot \ln \left(\frac{\mathrm{S}_{\mathrm{b}}}{\mathrm{S}_{\mathrm{b}}^{0}}\right)^{2}=-\frac{2 \mathrm{~L}_{\mathrm{b}} \cdot \kappa}{\mathrm{S}_{\mathrm{b}}^{0}}$

The accuracy of this mathematical approach has been discussed in detail in a previous publication where various extrapolation methods were implemented and compared [22]. In a similar way, the errors associated to the extrapolation technique applied to the current experimental datasets are below the uncertainties due to the measurement of the radii as discussed in the following paragraphs. Thus, the extrapolation model does not seem to have a significant influence on the derivation of the 
laminar flame speeds. In support of this result, a different criterion which was originally proposed by Wu et al. [30] based on the analyses of the product between Markstein and Karlovitz numbers was also used in order to estimate the uncertainty of the extrapolation process. Fig. 2 contains the results of such analysis which was performed considering the linear Markstein number and the Karlovitz number at the middle radius for all the experiments performed. Over the entire range of equivalence ratios considered here, the product $(\mathrm{Ma} \times \mathrm{Ka})$ is between -0.05 and 0.15 , condition for which negligible extrapolation uncertainty is expected.

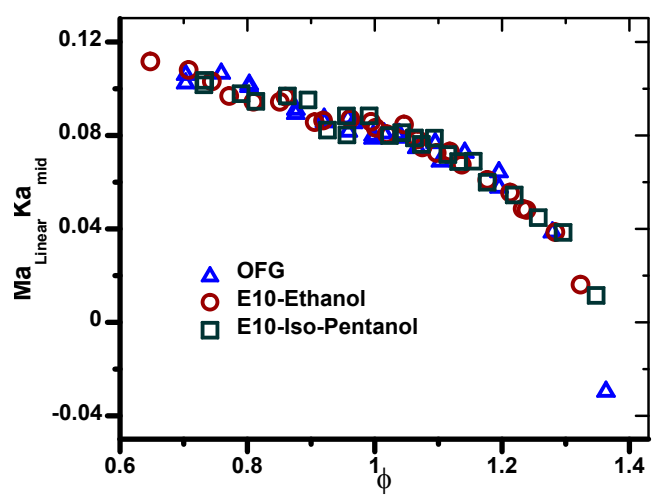

Fig. 2. (MaLinear $\mathrm{x}$ Kamid) as function of the equivalence ratio. Blue triangles: OFG, red circles: E10-Ethanol, green squares: E10-Iso-Pentanol.

Fig. 3 illustrates examples of the processed flame speed versus the stretch rate for different OFG/air mixtures. Fitting curves corresponding to the solutions of eqn. 1 have been presented in Fig. 3, while the experimental points have been obtained from the gradients of the radii. The slopes of such fitting curves are directly related to the Markstein lengths, which clearly decrease with increasing equivalence ratios $\left(\mathrm{L}_{b}\right.$ becomes negative for $\left.\phi=1.36\right)$. The minimum flame radius considered is between 10 and $15 \mathrm{~mm}$ in order to ensure that the ignition phase does not affect the results and that the stretch rate is not too high. The maximum radius is limited by the appearance of non-idealities in the experimental results, and it is normally included in the range between 30 and $35 \mathrm{~mm}$. Subsequently, the observation time is limited to the initial stage of the flame expansion where the 
pressure remains nearly constant as shown in Fig. 1 (for a maximum radius of $48 \mathrm{~mm}$ only about $0.8 \%$ of the total fuel is burned). Therefore, the relation $\mathrm{S}_{\mathrm{L}}{ }^{0}=\mathrm{V}_{\mathrm{S}} / \sigma$ can be used to determine the laminar flame speed at zero stretch $\mathrm{S}_{\mathrm{L}}{ }^{0}$, where $\sigma=\rho_{\mathrm{u}} / \rho_{\mathrm{b}}$ and $\rho_{\mathrm{u}}, \rho_{\mathrm{b}}$ are the unburned and burned densities of the mixture, respectively. The renormalized burned Markstein length $\mathrm{L}^{\prime}$, is determined with the relation $\mathrm{L}^{\prime}=\mathrm{L}_{\mathrm{b}} / \sigma . \mathrm{L}^{\prime}$ is presented for consistency to the fact that the unstretched laminar flame speed of the unburned gases is discussed in the manuscript (in fact we could re-write Eq. 1 in terms of $S_{u}, S_{u}^{0}$, and $L^{\prime}$ ). The densities of unburned and burned gases, $\rho_{u}$ and $\rho_{b}$, were calculated using $\operatorname{COSILAB}^{\circledR}[31]$ with the Equilibrium code.

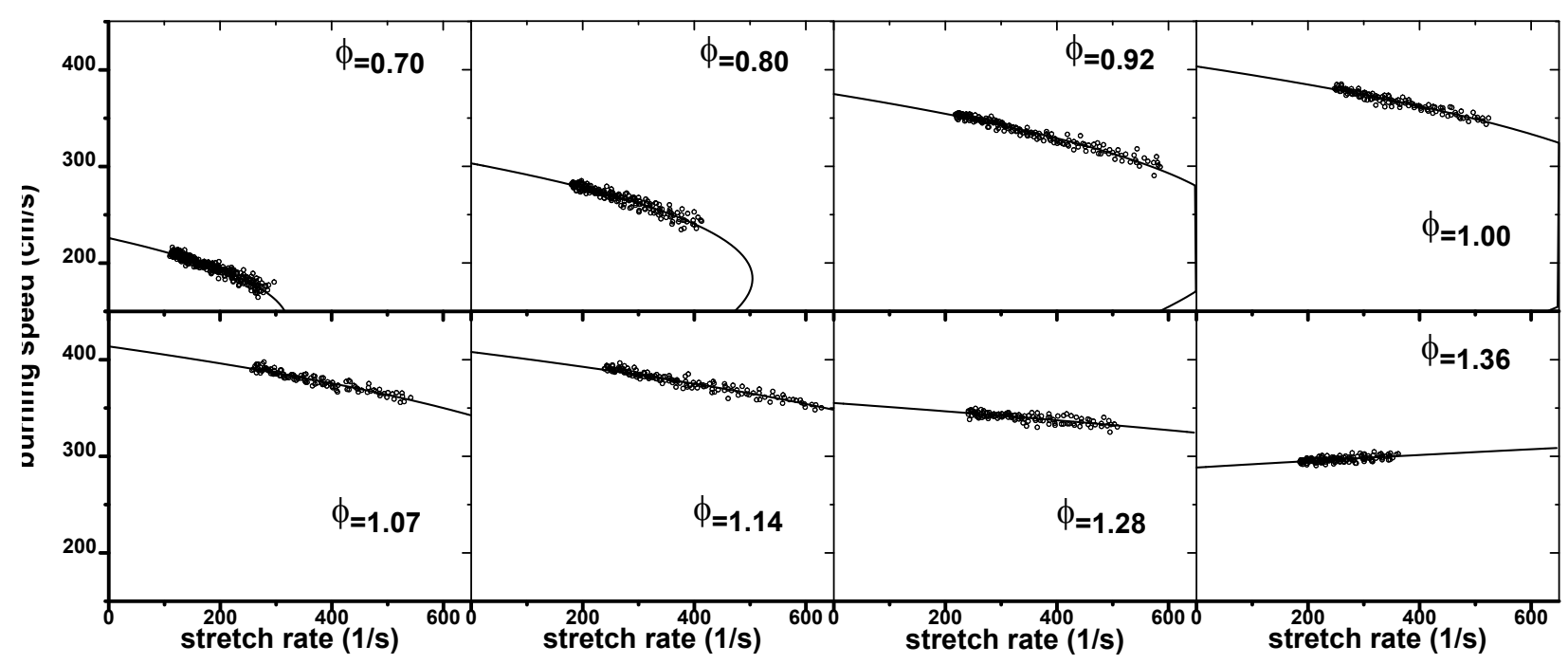

Fig. 3. Evolution of burning speed versus stretch rate for OFG / air mixtures. $P_{\text {in }}=0.1 \mathrm{MPa}$, $\mathrm{T}_{\text {in }}=483 \mathrm{~K}$.

The laminar flame speeds were measured at an initial pressure and temperature equal to $0.1 \mathrm{MPa}$ and $483 \pm 2 \mathrm{~K}$, respectively, and for $\phi$ from 0.65 to 1.36 . In particular, numerous experiments were performed nearly stoichiometric conditions which are typically encountered in gasoline engines. The experimental error was estimated to be around $2 \%$ maximum based on the error assessment procedure established in previous papers [20-22] (the absolute values of the errors on the flame speeds vary between 0.2 and $1.3 \mathrm{~cm} / \mathrm{s}$ ). No flame wrinkling due to flame instabilities was observed 
for the flame studied even for the highest equivalence ratios considered herein. Finally, the error due to heat loss by radiation was estimated based on the equation proposed by $\mathrm{Yu}$ et al. [32]. For all the experimental conditions, the radiation-correction terms is around $0.7 \mathrm{~cm} / \mathrm{s}$, thus of the same order of magnitude of the experimental uncertainties. If the corrections were applied to all the experimental points, a simple shift of the profiles by $0.7 \mathrm{~cm} / \mathrm{s}$ would be obtained. Such shift would not modify the considerations on the comparisons between the different fuel mixtures.
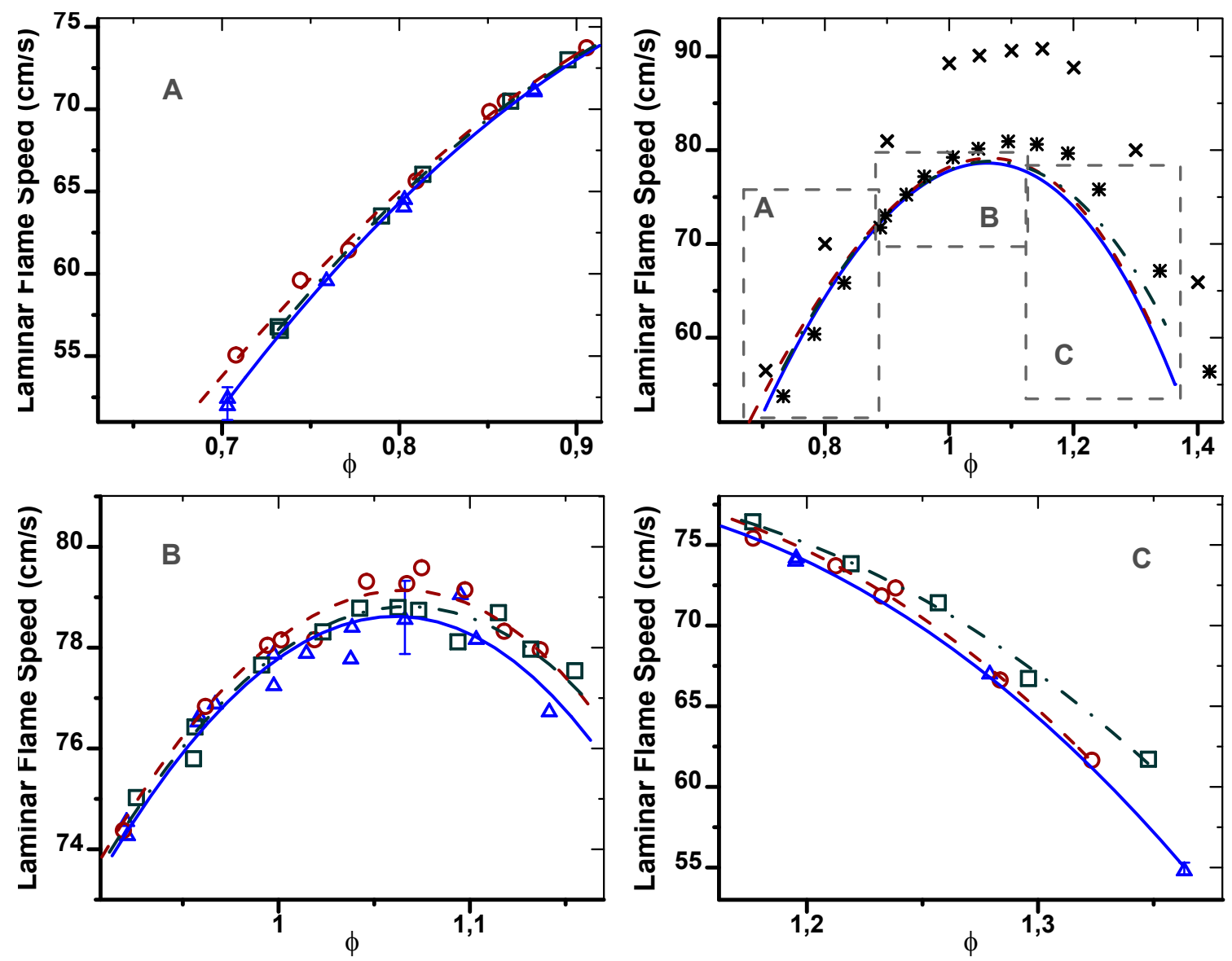

Fig. 4. Laminar flame speeds of OFG/air, E10-Ethanol/air, and E10-Iso-Pentanol/air mixtures at 0.1 MPa and 483 K. The lines represent the polynomial fits of the experimental results: — OFG, -- E10-Ethanol, $-\cdot-$ E10-IsoPentanol. Results from the literature at $473 \mathrm{~K}$ and $0.1 \mathrm{MPa}$ for: $X$ ethanol [9]; $*$ iso-pentanol [11]. A, B and C: zoom of the experimental data of the present study represented by symbols: blue triangles: OFG, red circles: E10Ethanol, green squares: E10-Iso-Pentanol.

The evolution of $\mathrm{S}_{\mathrm{L}}^{0}$ with the equivalence ratio of the three mixtures tested is presented in the Fig. 4. For the clarity of the discussion, the experimental results are compared in panels A, 
$\mathrm{B}$, and $\mathrm{C}$, while in the central panel containing all the experimental results only the polynomial fits of the experimental measurements are reported, together with the flame speed measurements for ethanol and iso-pentanol performed by our group and presented in previous publications [20, 22]. The polynomial fits well represent the experimental data. The discrepancy between the curves and the experimental data points is always below the experimental uncertainties (for $90 \%$ of the points, such discrepancy is below $0.5 \mathrm{~cm} / \mathrm{s}$ ).

In the lean region (panel A in Fig. 4), the experimental fits for the OFG/air mixtures and the E10-IsoPentanol/air mixtures overlay, thus the addition of iso-pentanol does not have any effect on the flame propagation of the oxy-free gasoline. The two curves start diverging at an equivalence ratio of around 1.1, thus at slightly fuel-rich conditions (panel B), while at even higher equivalence ratios (panel C) the E10-Iso-Pentanol/air mixtures propagate much faster than the corresponding OFG/air mixtures. At $\phi \sim 1.3$, the difference between the experimental curves reaches $\sim 3 \mathrm{~cm} / \mathrm{s}$, thus the presence of iso-pentanol significantly enhances the fuel propagation speed.

Different considerations apply to the E10-Ethanol/air mixtures. In this case, the addition of ethanol leads to an increment of the flame speed over the entire range of equivalence ratios studied herein. Such increment is relatively small and uniform over the experimental data, with a corresponding average value of $0.6 \mathrm{~cm} / \mathrm{s}$ based on the fitting curves. Although the error on the single measurement is larger than this value, the use of fitting curves which reproduce a large number of experimental data leads to a compensation of the opposite random errors, making the observed increment in the flame speed significant. As we will discuss later in the text, such increment is consistent with the modeling results. As for the case of iso-pentanol, the addition of ethanol does not change the position at which the maximum experimental flame speed is observed $(\phi \sim 1.07)$.

From an engineering point of view, for the best efficiency in a spark ignition engine the global equivalence ratio is around 1 . According to Fig. 4 , at $\phi=1, \mathrm{~S}_{\mathrm{L}}{ }^{0}$ is almost maximal and no 
difference between the OFG/air mixtures and the E10-Iso-Pentanol/air mixtures is observed. This indicates that blending iso-pentanol with the gasoline does not deteriorate the fuel properties in relation to the flame propagation compared the base case where pure gasoline is used. On the other hand, the addition of ethanol has beneficial effects, although the increment on the flame speed is minimal $(\sim 0.5 \%$ at $\phi=1)$. Thus, the effects on the laminar flame speed of blending the two alcohols studied here with the OFG fuel are nearly equivalent.

Figure 4 also reports the flame speeds of ethanol/air and iso-pentanol/air mixtures at $473 \mathrm{~K}$ [20, 22]. The comparison between the experimental sets shows that the ethanol/air flames propagate much faster compared to the case of iso-pentanol and gasoline over the entire range of equivalence ratios. On the other hand, the experimental profiles for iso-pentanol and the gasoline fuel are very close at fuel lean conditions, which may explain the fact that the two profiles for OFG and E10-Iso-Pentanol in Fig. 4 are almost identical at these conditions, while they diverge only at fuel rich conditions. It is interesting to notice how the effects of the addition of iso-pentanol to the OFG at high equivalence ratios are much more pronounced compared to the addition of ethanol, although the ethanol/air flames propagate faster compared to the iso-pentanol/air mixtures. On the other hand, the blending of ethanol and gasoline does not follow a linear mixing rule. The difference between the flame speeds of ethanol/air and OFG/air mixtures increases monotonically with the equivalence ratio, from 4 $\mathrm{cm} / \mathrm{s}$ at $\phi \sim 0.7$ to $\sim 16 \mathrm{~cm} / \mathrm{s}$ at $\phi \sim 1.3$, while the effects of the blending between OFG and ethanol are nearly independent of the equivalence ratio (as discussed above).

In addition to the laminar flame speeds, the experiments were used to derive the renormalized Markstein lengths $\mathrm{L}^{\prime}$ with an estimated maximum uncertainty of $10 \%$. The evolution of $\mathrm{L}^{\prime}$ is represented in Fig. 5. It seems that the three mixtures exhibit similar L'. A slight deviation is observed at the highest equivalence ratios, but more experimental points would be necessary in order to verify such hypothesis. The similarity between the experimental results presented in Fig. 5 
suggests that the three fuels will have a similar behavior with respect to the high stretch encountered in gasoline engines especially for equivalence ratios close to unity. Moreover, the results on the Markstein lengths support the observation that blending iso-pentanol with gasoline does not deteriorate the fuel properties compared to the ethanol/gasoline blends or the pure gasoline cases.

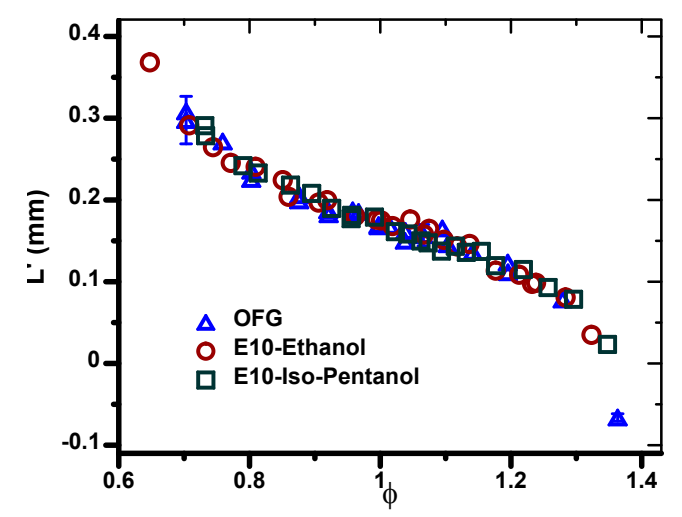

Fig. 5. Evolution of $L^{\prime}$ versus equivalence ratio at $0.1 \mathrm{MPa}$ and $483 \mathrm{~K}$. Blue triangles: OFG, red circles: E10Ethanol, green squares: E10-Iso-Pentanol.

\subsection{Ignition delay times}

The ignition delay time is defined as the interval between the pressure rise caused by the arrival of the shock wave at the end wall and the extrapolation to the baseline of the maximum rate of rise in the pressure signal due to the exothermic ignition event (Fig. 6, left graph). The maximum uncertainty on the ignition delay using this method is $\pm 2 \%$. In the lowest temperature range of our study, thus for long ignition delay times (normally above $1.1 \mathrm{~ms}$ ), evidences of pre-ignition pressure rise could be observed in the case of stoichiometric mixtures. An example is reported in the right graph of Fig. 6. The results associated with strong pre-ignition pressure rises are presented in Fig. S1. As shown, all the data with ignition delay times higher than $1.1 \mathrm{~ms}$ are affected by such phenomenon. In order to exclude the possibility that such pressure rise is due to non-idealities in the experimental technique, experiments were also performed removing the oxygen from the initial mixture, which is now composed only of the fuel and $\mathrm{N}_{2}$. In this case, no pressure rise was 
observed behind the reflected shock wave as shown in Fig. 6, suggesting that the pre-ignition is not due to non-ideal effects. However, in order to identify if this initial rise of the pressure is not due to an inhomogeneous ignition $[33,34]$, more experiments are needed with the implementation of a visualization of the ignition process by implementing a window at the end-flange which would allow the recording of the ignition and the identification of any inhomogeneous ignition with a flame propagation before the main ignition event. This will be addressed in the very near future.
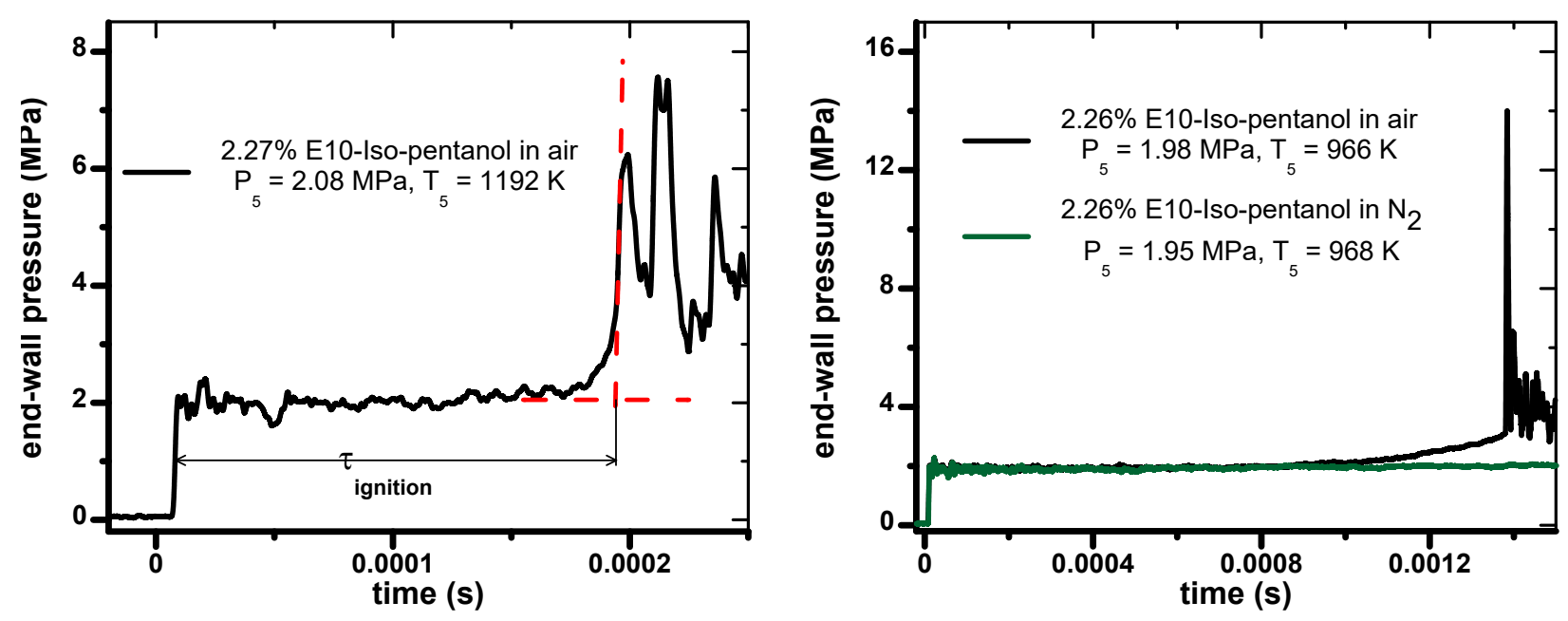

Fig. 6. Examples of end-wall pressure profiles for E10-Iso-Pentanol/air experiments at $\phi=1$ (black curves). Left: definition of the ignition delay time in this study. Right: comparison with a shock E10-Iso-Pentanol/ $\mathbf{N}_{2}$ (green curve).

For the shock tube study, the initial temperature was fixed at $403 \pm 2 \mathrm{~K}$ to avoid any condensation and the temperature behind the reflected shock wave was varied between 955 and $1284 \mathrm{~K}$. Considering the precision on the velocity and the initial temperature, the global uncertainty on $\mathrm{T}_{5}$ is $\pm 15 \mathrm{~K}$. The reflected shock pressures were equal to $2.13 \pm 0.33 \mathrm{MPa}$. Two different nominal equivalence ratios (0.5 and 1.0) were studied. The mixtures composition used are listed in Table 3 and the experimental data are presented in the supplemental file. 
Table 3

Mixture compositions for ignition delay experiments

\begin{tabular}{cccc}
\hline$\Phi$ & $\%$ fuel & $\% \mathrm{O}_{2}$ & $\% \mathbf{~ N}_{2}$ \\
\hline \multicolumn{4}{c}{ Fuel $=$ OFG } \\
0.5 & 1.11 & 20.67 & 78.22 \\
1 & 2.18 & 20.44 & 77.38 \\
\hline \multicolumn{4}{c}{ Fuel $=$ E10-Ethanol } \\
0.5 & 1.31 & 20.63 & 78.06 \\
1 & 2.58 & 20.36 & 77.06 \\
\hline \multicolumn{4}{c}{ Fuel $=$ E10-Iso-Pentanol } \\
0.5 & 1.15 & 20.66 & 78.19 \\
1 & 2.26 & 20.43 & 77.31 \\
\hline
\end{tabular}

The results of the ignition delay time experiments for OFG, E10-Ethanol and E10-Iso-Pentanol are summarized in Fig. 7a. The data of the three mixtures at $\phi=0.5$ are characterized by a small scatter. On the other hand, the difference between the experimental data obtained at stoichiometric conditions is more marked. In order to better appreciate these results, the fits of the experimental results based on the power law have been plotted in Fig. 7b. Prior to fitting the data, the pressure scaling of $\mathrm{P}^{-1.05}$ was adopted from the study of Gauthier et al. [6] and all the data of this study were normalized to $2 \mathrm{MPa}$ in Fig. $7 \mathrm{~b}$. At $\phi=0.5$, almost no difference on the delay is observed for the three mixtures even if the data of E10-Iso-Pentanol/air are slightly lower ( $\sim 6 \%$ on average in the range 1050-1260 K based on the experimental fits) compared to the E10-Ethanol and OFG fuels. The effects of ethanol addition are in this case almost negligible (around $1 \%$ average decrement in the ignition delay times). At stoichiometric conditions, a larger difference between the three curves was obtained. Indeed, the data for the oxy-free gasoline are higher than those for both blended fuels. In the range between $990 \mathrm{~K}$ and $1260 \mathrm{~K}$ the ignition delay times of ethanol/gasoline and isopentanol/gasoline blends in air are lower by $\sim 12 \%$ and $\sim 14 \%$ on average, respectively, compared to the OFG/air mixtures. It is interesting to notice how at $\phi=1.0$ and in the highest temperature range of our study the effects of ethanol and iso-pentanol additions seem to be similar, while the isopentanol/gasoline blends are characterized by lower ignition delay times at lower temperatures. The 
results presented in Fig. 7 indicate that replacing ethanol with iso-pentanol leads to reduced ignition delay times of the corresponding blend fuel. This should be considered in engine applications since it could be directly related to knock problems.

The OFG/air data are also compared with the data of Gauthier et al. [6] in Fig. 4b. In their paper, Gauthier et al. [10] studied the auto-ignition characteristics of n-heptane/air, gasoline/air, and ternary surrogate/air mixtures in a shock tube. We can observe an overall good agreement at $\phi=0.5$, with a difference of less than $10 \%$ for the two measurements performed by Gauthier et al. [6]. At stoichiometric conditions, the agreement between the experimental sets is excellent at low temperatures, although for $\mathrm{T}>1100 \mathrm{~K}$ the difference increases to around $16 \%$. Such discrepancy in the high temperature range of the studies may be mainly due to the different gasoline compositions. Although both gasolines do not contain oxygenated compounds, the fuel investigated by Gauthier et al. [6] contains more $\mathrm{C}_{5}$ napthenes and $\mathrm{C}_{5}-\mathrm{C}_{7}$ paraffins than the fuel used herein as well as less aromatics and isoparaffins.

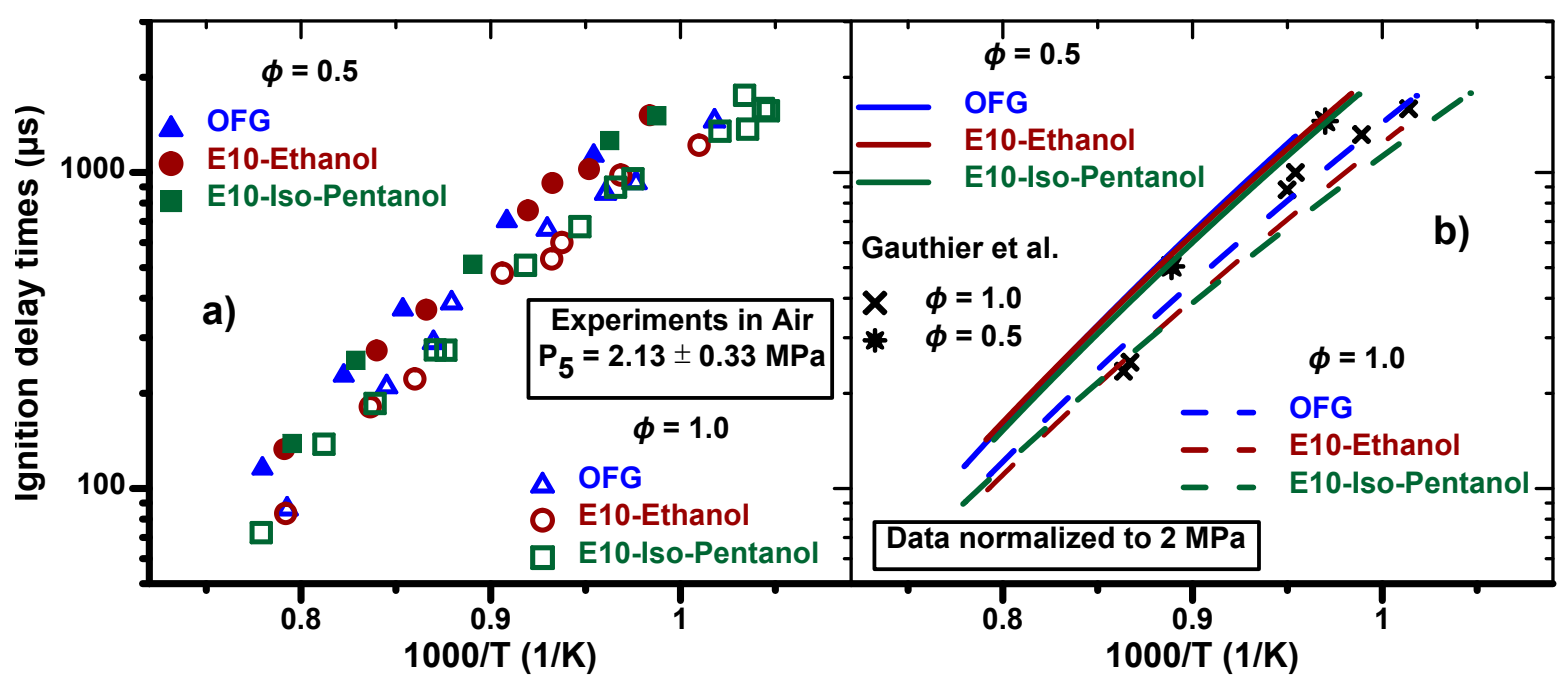

Fig. 7. Experimental ignition delay time measurements. (a) Data from this study: $\phi=1.0$ - blue empty triangles: OFG, red empty circles: E10-Ethanol, green empty squares: E10-Iso-Pentanol; $\phi=0.5$ - blue full triangles: OFG, red full circles: E10-Ethanol, green full squares: E10-Iso-Pentanol. (b) Fits of the data normalized to 2 MPa from this study compared with the literature $[6]: \phi=1.0---$ OFG, -- E10-Ethanol, -- E10-Iso-Pentanol; $\phi=0.5-$ OFG, — E10-Ethanol, — E10-Iso-Pentanol. 


\subsection{Surrogate fuel simulations}

The formulation of surrogate fuels able to mimic the physical and chemical properties of real fuels is an essential area of research for the transition between the experimental results on real fuels and the kinetic modeling applied to engine simulations. In the present work, two surrogate fuels have been tested based on the works by Morgan et al. [35] and Cai and Pitsch [36]. The surrogates have been determined implementing the methods proposed in the above-mentioned studies based on the specific properties of the current OFG fuel. Both surrogates, whose compositions are reported in Table 4, are composed of n-heptane, iso-octane, and toluene (PRF/toluene). Indeed, the method proposed by Cai and Pitsch [36] is an extension of the work by Morgan et al. [35] in the sense that the surrogate formulation is based not only on the MON/RON values as in [35] but also on the fuel $\mathrm{C}_{\mathrm{x}} \mathrm{H}_{\mathrm{y}} \mathrm{O}_{\mathrm{z}}$ molecular formula. The percentages of n-heptane in the two formulations are very similar (around 16\%). On the other hand, the main component of the surrogate calculated based on Morgan et al. [35] is toluene (mole percentage of $\sim 54 \%$ ) compared to $~ 30 \%$ of iso-octane, while the opposite is true for the formulation based on Cai and Pitsch [36] (the percentages are around $37 \%$ and $47 \%$ for toluene and iso-octane, respectively). Since the kinetic model by Cai and Pitsch [36], selected here to perform the modeling simulations, was validated against experimental ignition delay time and laminar flame speed measurements of PRF/toluene/ethanol single-components and mixtures, the fuel surrogates with addition of ethanol were also considered (Table 4). The compositions of the surrogate/ethanol surrogate/iso-pentanol mixtures were calculated by considering the mass percentage of ethanol as in Table 2 and re-adjusting the mole fraction of the surrogate fuel components (n-heptane, iso-octane, toluene) in the same proportions. The development of a novel sub-mechanism for iso-pentanol is beyond the scope of the current investigation, thus the modeling section will be focused on the OFG and the E10-Ethanol results. Simulations of laminar flame speeds and ignition delay times for the different surrogate mixtures were performed at the 
conditions encountered in the current experiments using $\operatorname{COSILAB}^{\circledR}[31]$. In particular, for the flame speed calculations the one-dimensional freely-propagating flame system was solved, with GRAD and CURV values equal to $10^{-5}$ and a spatial domain from -1 to $10 \mathrm{~cm}$. For these GRAD and CURV values, the final solution is independent from the adaptative gridding procedure. All the flame calculations were performed using multi-component transport properties and including the Soret effects. The ignition delay times were calculated based on the pressure profiles assuming adiabatic and constant volume conditions behind the reflected shock wave.

Table 4

\begin{tabular}{ccccc}
\multicolumn{5}{c}{ Surrogate mixture compositions (mole fractions in \%) } \\
\hline Fuel & $\mathbf{C}_{\mathbf{7}} \mathbf{H}_{\mathbf{1 6}}$ & $\mathbf{i}-\mathbf{C}_{\mathbf{8}} \mathbf{H}_{\mathbf{1 8}}$ & $\mathbf{C}_{\mathbf{6}} \mathbf{H}_{\mathbf{5}} \mathbf{C H}_{\mathbf{3}}$ & $\mathbf{C}_{\mathbf{2}} \mathbf{H}_{\mathbf{5}} \mathbf{O}$ \\
\hline \multicolumn{5}{c}{ Morgan et al. } \\
OFG & 16.40 & 29.66 & 53.94 & 0.00 \\
E10-Ethanol & 13.17 & 23.81 & 43.30 & 19.72 \\
\hline \multicolumn{5}{c}{ Cai and Pitsch } \\
OFG & 15.95 & 47.25 & 36.80 & 0.00 \\
E10-Ethanol & 12.62 & 37.36 & 29.10 & 20.92 \\
\hline
\end{tabular}

The experimental laminar flame speed results and corresponding surrogate simulations are reported in Fig. 8. The experimental results on the real fuels are well reproduced by the simulations performed with both fuel surrogates. In particular, the shape of the experimental and modeling profiles are in excellent agreement for the case of the surrogate based on Morgan et al. [35], with a slight overprediction of the maximum laminar flame speeds $(\sim 2 \mathrm{~cm} / \mathrm{s}$, which corresponds to $\sim 2 \%$ of the experimental values). On the other hand, the profiles obtained with the surrogate based on Cai and Pitsch [36] presented in Fig. 8b are slightly shifted towards higher equivalence ratios compared to the experimental profiles although the maximum laminar flame speed values are better reproduced (discrepancy $\sim 1 \%$ ). This is somehow expected since the flame propagation is affected by the rate of heat released during combustion, thus function also of the carbon and hydrogen content in the fuel. A better match of the fuel molecular formula as in the method proposed by Cai and Pitsch [36] should lead to a better prediction of the heat release and consequently of the absolute value of the 
maximum flame speed. More importantly, for both surrogates the effects of the ethanol addition are similar to the ones observed experimentally, with an increment of around $1 \mathrm{~cm} / \mathrm{s}$ on average in the flame speed (against $0.6 \mathrm{~cm} / \mathrm{s}$ from experiments). Thus, both surrogate formulations can be used to predict the flame speeds of real fuels also in the presence of ethanol addition.

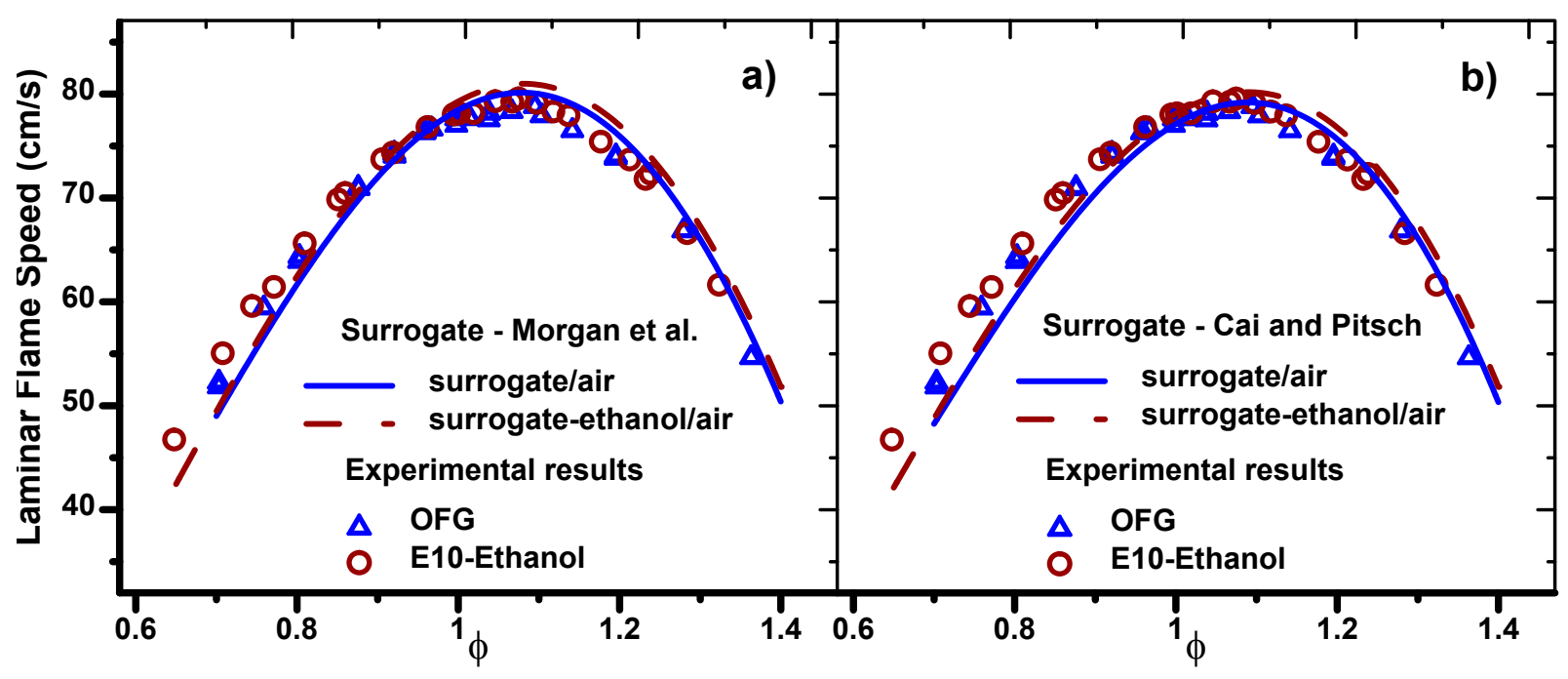

Fig. 8. Laminar flame speeds of OFG/air, E10-Ethanol/air, and corresponding surrogate/air mixtures at 0.1 MPa and $483 \mathrm{~K}$. Experimental results for real fuels: blue triagles: OFG, red circles: E10-Ethanol. Simulations for surrogates based on a) Morgan et al. [35] and b) Cai and Pitsch [36]: — surrogate, - - surrogate/ethanol.

A detailed kinetic analysis of the reasons for the increase of the laminar flame speed with addition of ethanol is behind the scope of the present study. On the other hand, preliminary analyses were performed. In the equivalence ratio range considered, the percentage increment in the calculated laminar flame speed with ethanol addition is $1.7 \%$, which might be due effects of thermal diffusivity, flame temperature, and/or chemistry. The adiabatic flame temperatures with and without ethanol differ by no more than $5 \mathrm{~K}$ over the entire equivalence ratio range, while the thermal diffusivity by no more than $0.06 \%$. Thus, the only factor which may explain the increment in the laminar flame speed is the fuel chemistry. Sensitivity analyses at an equivalence ratio of 1.1 showed that the reactions which influence the speed calculations are the same in the two cases with and without ethanol. On the other hand, the reactions involving $\mathrm{HCO}, \mathrm{CH}_{3}, \mathrm{HO}_{2}$, and $\mathrm{C}_{2} \mathrm{H}_{3}$ show 
increased sensitivity coefficients when ethanol is added to the fuel mixture (above $8 \%$ increase). Indeed, most of these species are produced in larger amounts in the flame with ethanol added to the OFG. The detailed analyses of the reaction pathways responsible for the formation of these species in both flames is quite complicated and not considered in the present study.

The ignition delay time simulations obtained with the two surrogate fuels are presented in Fig. 9 together with the experimental data obtained in the present work. The surrogate based on the method by Morgan et al. [35] is characterized by ignition delay times which are longer than the experimental ones for both equivalence ratios (Fig. 9a). Better agreement can be observed for the results in Fig. 9b which are related to the surrogate formulation by Cai and Pitsch [36]. Once again, the fact that in this case the molecular formula of the fuel is considered should explain the better accuracy of the surrogate formulation. In particular, the experimental results for temperatures above $\sim 1100 \mathrm{~K}$ are very similar to the ignition delay times of the corresponding surrogates with the only exception of the OFG stoichiometric data, while at lower temperatures a divergence can be observed. It is interesting to notice how for the fuel lean case the addition of ethanol to the surrogate mixture leads to a shift in the ignition curve towards lower values with an average decrement of $\sim 16 \%$. This value is much higher compared to the experimental results (the ignition delay times of OFG/air and E10-Ethanol/air mixtures are very similar). In addition, the two stoichiometric curves in Fig. $9 \mathrm{~b}$ converge in the low temperature range of the current study, while at high temperatures the surrogate ignition delay times are larger than the OFG/air ones. Despite these discrepancies, the results in Fig. $9 \mathrm{~b}$ are quite promising considering the fact that a complex fuel as the one studied here is compared to a mixture of only three components. 


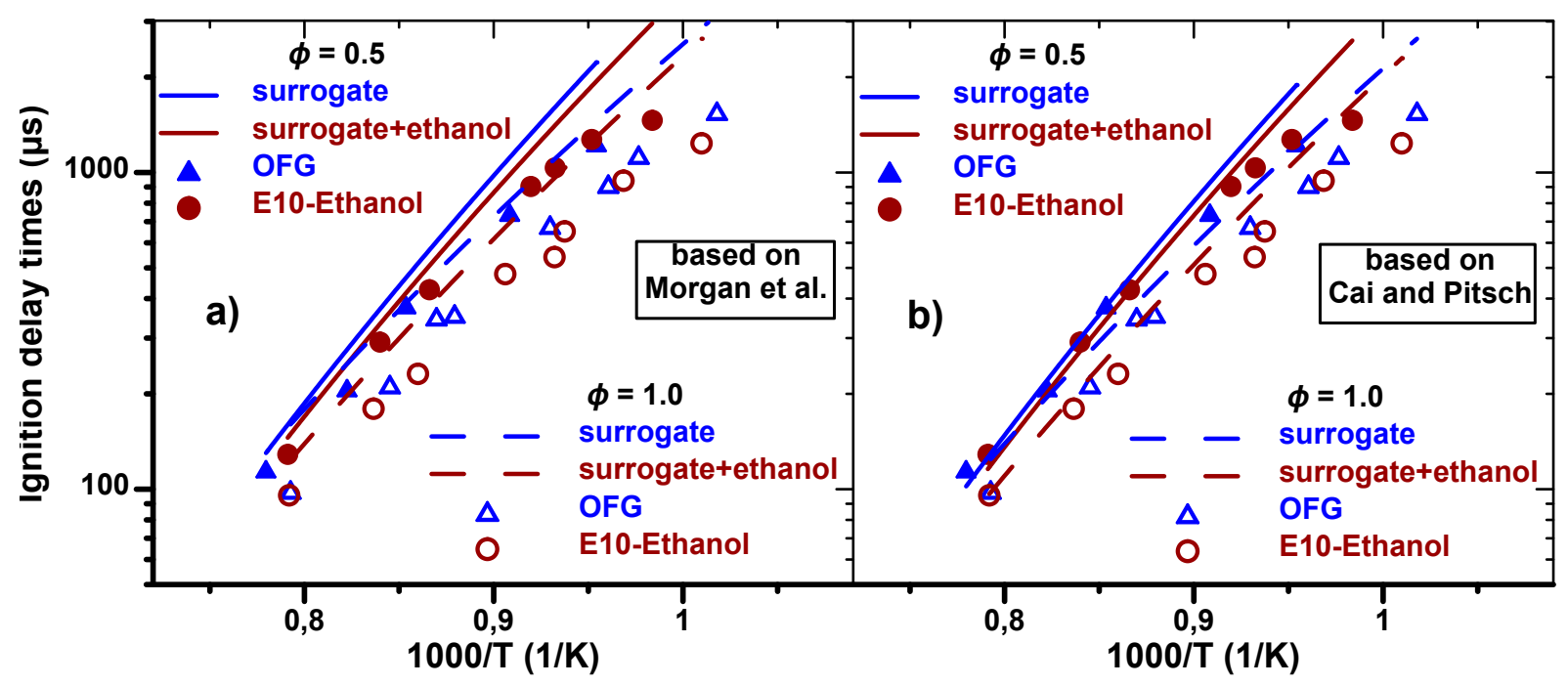

Fig. 9. Ignition delay times of OFG/air, E10-Ethanol/air, and corresponding surrogate/air mixtures. Experimental results for real fuels: $\phi=1.0$ - blue empty triangles: OFG, red empty circles: E10-Ethanol; $\phi=0.5$ - blue full triangles: OFG, red full circles: E10-Ethanol. Simulations for surrogates based on a) Morgan et al. [35] and b) Cai and Pitsch [36]: $\phi=1.0$ - - - surrogate, - - surrogate/ethanol; $\phi=0.5$ - — surrogate, _ surrogate/ethanol. Data normalized to 2 MPa.

In order to further investigate the reasons behind the discrepancies observed between the simulations and the ignition delay time measurements, additional simulations were performed with a different chemical kinetic model [37] and i) the surrogate based on the work by Cai and Pitsch [36] or ii) the (iso-octane/toluene/n-heptane/1-hexene) surrogate as proposed by McCormick et al. [38]. The latter was also experimentally investigated by Cooper et al. [39] using shock tube techniques for ignition delay time measurements in their work on gasoline surrogates and their blends with ethanol and methyl acetate. It is worth mentioning that the surrogate by McCormick et al. [38] has estimated RON and MON values of 90.3 and 84.7, thus slightly different than the current OFG fuel. On the other hand, the mole fractions of the different components are quite representative of the corresponding classes in the OFG fuel. In fact, the surrogate is composed of $14.4 \% \mathrm{n}$-heptane, $33.2 \%$ toluene, $46.7 \%$ iso-octane, and 5.6\% 1-hexene (in mole fraction), while the OFG fuel of $10.8 \%$ paraffins + naphthenes, $34.1 \%$ aromatics, $50.9 \%$ iso-paraffins, and $4.1 \%$ olefins (analysis based on the known components). The tested kinetic model is the well-established LLNL model for gasoline surrogates [37], validated against experimental data on n-heptane, iso-octane, toluene, and C5- 
C6 olefins. The results are presented in Fig. 10a for the pure OFG fuel and Fig. 10b for the OFG/ethanol mixtures. The use of the LLNL model improve sensibly the prediction capabilities even with the three-component surrogate based on the work by Cai and Pitsch [36] (blue lines). The addition of the 1-hexene component as in the formulation by McCormick et al. [38] further improves the correspondence between the simulations and the experiments (red lines) although the difference between the two surrogates is not negligible only in the low-temperature range of our experiments. If we don't consider the points corresponding to simulations above $2 \mathrm{~ms}$ ignition delay times where the experimental measurements may be affected by the observed pressure rise for stoichiometric conditions, the discrepancies between all the experimental data but one and the simulations is below $25 \%$. The chemical kinetic model also reproduces very well the influence of the ethanol addition on the ignition delay time properties of the fuel. As mentioned in the experimental section, the average decrements in the ignition delay times for fuel-lean and stoichiometric mixtures are around 1\% and $12 \%$, while the simulated ones are $3 \%$ and $9 \%$, respectively. It is now possible to conclude that the two surrogates well represent the current studied OFG fuel, although the utilization of a more complex mixture with addition of the olefin component slightly improves the prediction capabilities.

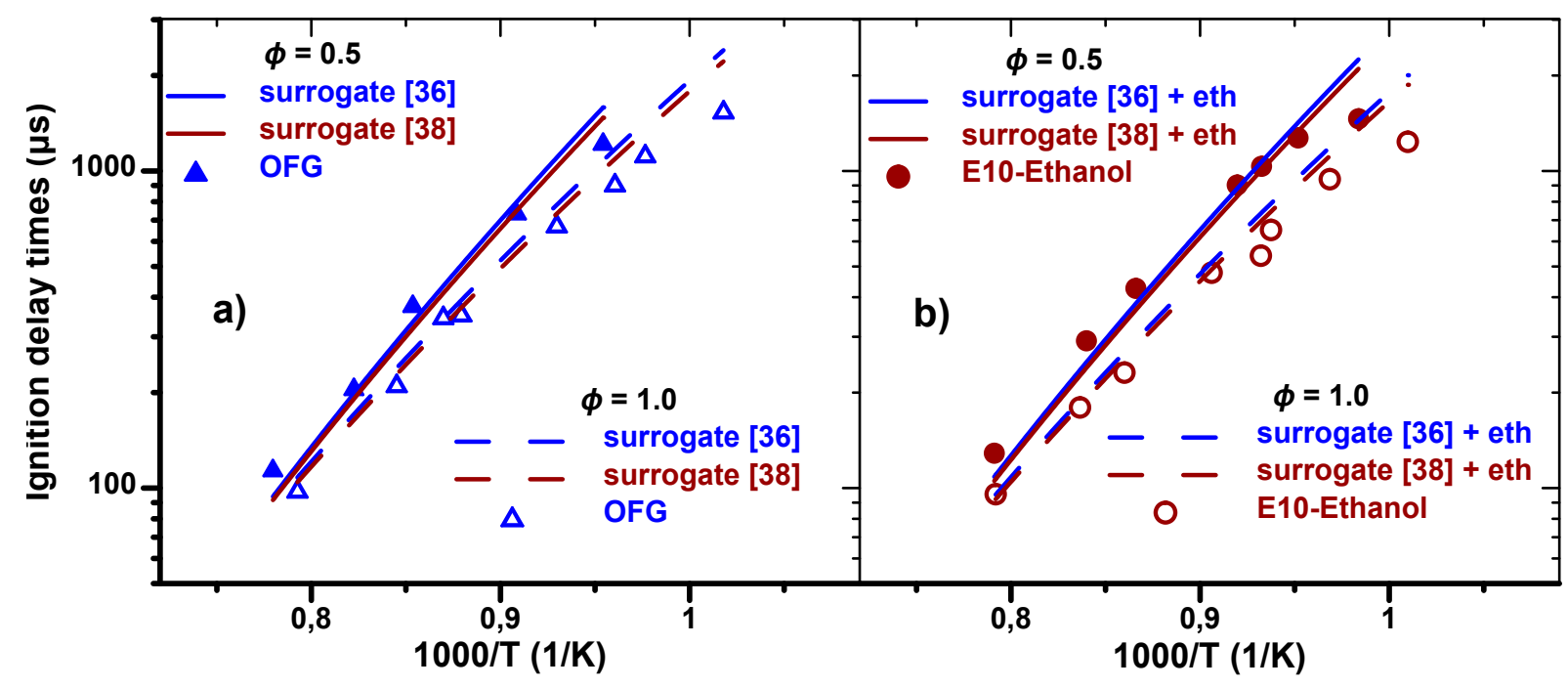

Fig. 10. Ignition delay times of OFG/air, E10-Ethanol/air, and corresponding surrogate/air mixtures. Experimental results for real fuels: $\phi=1.0$ - blue empty triangles: OFG, red empty circles: E10-Ethanol; 
$\phi=0.5$ - blue full triangles: OFG, blue full circles: E10-Ethanol. Simulations with the LLNL model [37] for surrogates based on Cai and Pitsch [36] (blue lines) and McCormick et al. [38] (red lines) for a) OFG, b) E10Ethanol. $\phi=1.0$ - dashed lines; $\phi=0.5$ - solid lines. Data normalized to 2 MPa.

In addition to perform experiments on the four-components surrogate, Cooper et al. [39] used their data together with other shock tube data available in the literature on different fuel surrogates and gasoline fuels to provide a correlation for the ignition delay times as function of the equivalence ratio, the pressure, and the temperature conditions. The comparison between the correlation results applied to our experimental conditions and the current experimental results are presented in Fig. 11. Considering the scattering present in the data analyzed by Cooper et al. [39], the match between the correlation and the data is quite good, confirming once again the validity of the present experimental data sets compared to the previous studies focused on gasoline fuels and surrogates.

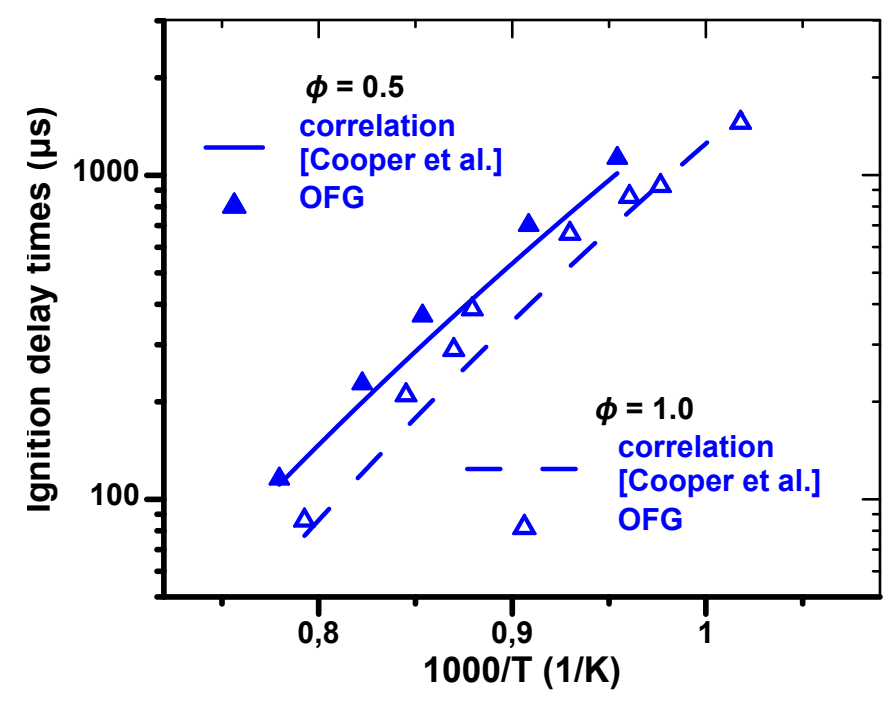

Fig. 11. Ignition delay times of OFG/air mixtures and correlation functions by Cooper et al. [39].

\section{Conclusions}

The combustion properties of gasoline/air, gasoline/iso-pentanol/air, and gasoline-ethanol/air mixtures were investigated. New measurements of laminar flame speeds at an initial temperature of $483 \mathrm{~K}$, an initial pressure of $0.1 \mathrm{MPa}$ and equivalence ratios between 0.65 and 1.36 were 
obtained in a spherical reactor. These data were compared with pure ethanol and iso-pentanol flames from the literature. It was observed that the iso-pentanol flame speeds are closer to the three mixtures tested in this study, showing a similar behavior of iso-pentanol with gasoline and gasoline/alcohol blends. The ignition delay times were measured behind reflected shock waves in a high pressure heated shock tube. The experiments were conducted at $2 \mathrm{MPa}$ over a temperature range from 955 to $1284 \mathrm{~K}$. Two equivalence ratios were tested, 0.5 and 1 . The ignition delay times of the commercial gasoline were compared with the literature and an overall good agreement was found for both equivalence ratios. From these experiments in shock tube and spherical reactor, it was shown that at nearly stoichiometric conditions (typical of optimized engines) the addition of iso-pentanol does not significantly affect the flame speed of the fuel/air mixture compared to the ethanol case, while the contrary is true concerning the ignition delay time measurements. In fact, the addition of iso-pentanol reduces the time necessary for ignition in a more significant proportion than ethanol. Two surrogate mixtures were also tested against the real fuel measurements (OFG and E10-Ethanol) using kinetic modeling with a reduced model from the literature. The comparison between surrogate and real fuel properties are quite promising although some discrepancies were observed especially for the ignition delay time measurements. Additional analyses showed how the use of a different detailed chemical kinetic model and a more complex surrogate fuel leads to accurate predictions of the ignition properties.

\section{Acknowledgements}

The authors acknowledge the financial support of le Label CAPRYSSES and the help of Claire Grégoire for some of the shock tube experiments. 


\section{References}

1. A. S. AlRamadan, J. Badra, T. Javed, M. Al-Abbad, N. Bokhumseen, P. Gaillard, H. Babiker, A. Farooq, S. Mani Sarathy, Combust. Flame, 162 (2015) 3971-3979.

2. P. Dirrenberger, P.A. Glaude, R. Bounaceur, H. Le Gall, A. Pires da Cruz, A.A. Konnov, F. Battin-Leclerc, Fuel 115 (2014) 162-169.

3. S. Mani Sarathy, P. Oßwald, N. Hansen, K. Kohse-Höinghaus, Prog. Energ. Comb. Science 44 (2014) 40-102.

4. S. Park, S. H. Chung, T. Lu, S. Mani Sarathy, Energy Fuels 29 (2015) 7584-7594.

5. G. T. Kalghatgi, SAE paper 2005-01-0239, 2005. https://doi.org/10.4271/2005-01-0239.

6. B. M. Gauthier, D. F. Davidson, R. K. Hanson, Combust. Flame 139 (2004) 300-311.

7. D. F. Davidson, J. K. Shao, R. Choudhary, M. Mehl, N. Obrecht, R. K. Hanson, Proc Combust Inst 37 (4) (2019) 4885-4892.

8. D. F. Davidson, Y. Zhu, J. Shao, R. K. Hanson, Fuel 187 (2017) 26-32.

9. L. Cai, A. Ramalingam, H Minwegen, K. A. Heufer, H. Pitsch. Proc Combust Inst 37 (2019) 639647.

10. S. M. Sarathy, G. Kukkadapu, M. Mehl, W. Wang, T. Javed, S. Park, M. A. Oehlschlaeger, A. Farooq, W. J. Pitz, C-J Sung, Proc Combust Inst 35 (2015) 249-257.

11. S. M. Sarathy, G. Kukkadapu, M. Mehl, T. Javed, A. Ahmed, N. Naser, A. Tekawade, G. Kosiba; M. Al Abbad, E. Singh, S. Park, M. Al Rashidi, C. S. Ho, W. L. Roberts, M. A.Oehlschlaeger, S. Chih-Jen, A. Farooq, Combust. Flame 169 (2016) 171-193.

12. S. Jerzembeck, N. Peters, P. Pepiot-Desjardins, H. Pitsch, Combust Flame, 156 (2009) 292-301. 
13. O. Mannaa, M. S. Mansour, W. L. Roberts, S. H. Chung, Combust Flame 162 (2015) 2311-2321.

14. L. Sileghem, V.A. Alekseev, J. Vancoillie, K.M. Van Geem, E.J.K. Nilsson, S. Verhelst, A.A. Konnov, Fuel 112 (2013) 355-365.

15. Y. Yang, J. E. Dec, N. Dronniou, B. Simmons, SAE International Journal of Fuels and Lubricants 3 (2010) 725-741.

16. G. Dayma, C. Togbé, P. Dagaut, Energy \& Fuels 25 (2011) 4986-4998.

17. T. Tsujimura, W. J. Pitz, F. Gillespie, H. J. Curran, B. W. Weber, Y. Zhang, C.-J. Sung, Energy \& Fuels 26 (2012) 4871-4886.

18. S. Mani Sarathy, S. Park, B. W. Weber, W. Wang, P. S. Veloo, A. C. Davis, C. Togbe, C. K. Westbrook, O. Park, G. Dayma, Z. Luo, M. A. Oehlschlaeger, F. N. Egolfopoulos, T. Lu, W. J. Pitz, C.-J. Sung, P. Dagaut, Combust. Flame 160 (2013) 2712-2728.

19. Q. Li, C. Tang, Y. Cheng, L. Guan, Z. Huang, Energy \& Fuels 29 (2015) 5334-5348.

20. D. Nativel, M. Pelucchi, A. Frassoldati, A. Comandini, A. Cuoci, E. Ranzi, N. Chaumeix, T. Faravelli, Combust. Flame 166 (2016) 1-18.

21. M. Aghsaee, D. Nativel, M. Bozkurt, M. Fikri, N. Chaumeix, C. Schulz, Proc. Combust. Inst. 35 (1) (2015) 393-400.

22. A. Comandini, G. Pengloan, N. Chaumeix, Combust. Flame 173 (2016) 425-440.

23. F. Douce, N. Djebaïli-Chaumeix, C.-E. Paillard, C. Clinard, Proc. Combust. Inst. 28 (2) (2000) 2523-2529.24. Gaydon and Hurle "The shock-tube in high-temperature chemical physics", Chapman and Hall Ltd, London, 1963.

25. E. R. Ritter, J. Chem. Inf. Comput. Sci. 1991, 31, 3, 400-408

26. M. Barone, N. Chaumeix, A. Comandini, G. Continillo, S. Lombardi, D. Nativel, 
Unsupervised analysis of experiments of laminar flame propagation in a spherical enclosure, AIP Conference Proceedings 1790, 1100003 (2016); https://doi.org/10.1063/1.4968710.

27. J. Goulier, K. Bizon, N. Chaumeix, N. Meynet, G. Continillo. „Numerical assessment of accurate measurements of laminar flame speed”, AIP Conference Proceedings 1790, 110006 (2016); https://doi.org/10.1063/1.4968713

28. Matlab, The MathWorks, Inc. Version 2012b. www.mathworks.com.

29. A. P. Kelley, C. K. Law, Combust. Flame 156 (2009) 1844-1851.

30. F. Wu, W. Liang, Z. Chen, Y. Ju, C. K. Law, 35 (2015) 663-670.

31. COSILAB, The Combustion Simulation Laboratory, Version 3.3.2. http://www.SoftPredict.com. Rotexo GmbH \& Co. KG, Haan, Germany, (2009).

32. H. Yu, W. Han, J. Santner, X. Gou, C. H. Sohn, Y. Ju, Z. Chen, Combust. Flame 161 (2014) $2815-2824$.

33. M. Figueroa-Labastida, J. Badra, A. Farooq, Combust Flame 224 (2021) 33-42.

34. J. Shao, R. Choudhary, A. J. Susa, D. F. Davidson, R. K. Hanson, Proc Combust Inst 38 (2021) 911-918.

35. N. Morgan, A. Smallbone, A. Bhave, M. Kraft, R. Cracknell, G. Kalghatgi, Combust. Flame 157 (2010) 1122-1131.

36. L. Cai, H. Pitsch, Combust. Flame 162 (2015) 1623-1637.

37. M. Mehl, W.J. Pitz, C.K. Westbrook, H.J. Curran, Proc Combust Inst 33 (2011) 193-200.

38. R.L. McCormick, G. Fioroni, L. Fouts, E. Christensen, J. Yanowitz, E. Polikarpov, K. Albrecht, 
D.J. Gaspar, J. Gladden, A. George, SAE Int. J. Fuels Lubr. 10 (2017) 442-460.

39. S. P. Cooper, O. Mathieu, I. Schoegl, E. L. Petersen, Fuel 275 (2020) 118016. 